\title{
Correspondence
}

\section{CPA: should it carry a government health warning?}

Sir: Watson (Psychiatric Bulletin, July 1997, 21. 432-434) described a recent "aversion experience" of using the Care Programme Approach (CPA). Watson claims that a CPA meeting held with a client, referred to as B., precipitated a violent suicide attempt. Although described by Watson as, "The last straw which triggered her behaviour", the CPA is set up as the villain of the piece. Several other possible stressors were identified by Watson and B., including the imminent departure of B.'s keyworker, B.'s approaching discharge from hospital, and B.'s fear of Watson's impending retirement. In concert, these factors would plausibly provide a sufficient trigger for a vulnerable individual, but it is a CPA needs assessment meeting that is made to shoulder the blame.

In general, Watson labels the CPA "reductionist". and considers it to be a waste of valuable clinical time. Watson goes on to say of B. that, "her 'needs' were for love, for closeness, and for something to fill up the sense of emptiness, not the list we had written on the page (CPA form)"; and comments that, "A need for closeness and holding do not fit easily into the CPA form." They should not. These are inappropriate objections to an approach designed to promote good professional practice. Could one even imagine a 'professional' psychiatric system for the provision of love, closeness, and existential fulfilment? It is strangely naive to complain that the CPA is not a life-partner.

Watson offers, honestly, that, "On this occasion I did not pick up the degree of distress which the patient was feeling, in spite of knowing her very well indeed"; but complains that it was the setting of a CPA needs assessment meeting that made it difficult to attend to B.'s emotional state. To make the CPA the scapegoat for a simple lapse in professional sensitivity is unreasonable.

It would be a shame if these misplaced objections to the CPA were to deter Watson and other professionals from carrying out the comprehensive assessment of needs that is a central pillar of the CPA's formalisation of good practice.

JASON WHEELER, Department of Psychiatry, De La Pole Hospital, Willerby, Hull HU1O 6ED

Sir: I would like to thank $\mathrm{Dr}$ Wheeler for responding to my account of a recent experiment of using the CPA. The points he raises are interesting, but they reflect a lack of understanding of what I was attempting to demonstrate. My main aim was to point out the patient's perception of the process. He claims that I unfairly portrayed the CPA as the "villain of the piece", when it was the patient who had clearly reported that for her it was indeed the last straw. The other factors mentioned were obviously important and I was careful not to ignore them.

He has interpreted my comment that the need for love, closeness and understanding do fit on the CPA form literally as my "naive wish for it to be a life-partner". Clearly this is not my wish. The point was the patient's awareness that "needs" as written on the page were very inadequate to describe what she was feeling and that the discrepancy resulted in distress.

As for the "lapse in professional sensitivity": surely, unless we try to examine which elements in the interview or surroundings contribute to such lapses, we risk repeating them. My hope was that the account would stimulate some thought about the CPA process so that there would be less likelihood of a blind acceptance of it.

P. E. WATson, Consultant Psychiatrist, Derwent Clinic, Shotley Bridge General Hospital, Shotley Bridge, Consett, County Durham DH8 ONP

\section{Tardive dyskinesia - how is it prevented and treated?}

In their otherwise outstanding review of current knowledge regarding the treatment of tardive dyskinesia (TD) (Psychiatric Bulletin, July 1997, 21, 422-425), Duncan et al significantly underestimate both the quantity and quality of the evidence regarding the efficacy of clozapine in the treatment of TD.

Although two early double-blind studies with a total of 15 patients failed to demonstrate a beneficial effect of clozapine on TD, these were brief, used extremely small doses and came from the same group (Casey, 1989). There have since been 10 studies, nine open and uncontrolled with a total of approximately 200 subjects from six different centres (see Young et al, 1997), and one an elegant double-blind study which compared clozapine to haloperidol plus benztropine in 32 patients (Tamminga et al, 1994). All the open-label studies found a significant reduction in TD, with scores on the Assessment of Involuntary Movement Scale reduced by greater than $50 \%$ in $40-100 \%$ of patients, and complete 
remission in $10-30 \%$ of patients. In the controlled trial performed by Tamminga et al, patients that received clozapine not only had a significant improvement in their TD, when compared to both their own baseline and to those subjects receiving haloperidol, but maintained this improvement for the 12-month duration of the trial. Clozapine doses in all of these studies were similar to those typically used to treat psychosis.

In summary, there exist considerable data, from a wide variety of centres, and including double-blind evidence, all consistent with the hypothesis that clozapine is effective in the treatment of tardive dyskinesia. While clozapine's mechanism of action in TD may remain unclear (Young et al, 1997), its efficacy in this chronic, severe, and often disabling condition appears to be beyond doubt.

CASEY, D. E. (1989) Clozapine: neuroleptic-induced EPS and tardive dyskinesa. Psychopharmacology, 89, S47-S53.

TAMminga, C. A., ThaKer, G. K., MORAN, M., et al (1994) Clozapine in tardive dyskinesla: observations from human and animal model studies. Joumal of Clinical Psychiatry. 65 (suppl B), 102-106.

YOUNG, C. R., LONGHURST, J. G., BOWERS, M. B., et al (1997) The expanding indications for clozapine. Joumal of Clinical and Experimental Psychopharmacology, 6, 1-20.

JAMES G. LONGHURST and ERICA L. WEISS, Department of Psychiatry and Connecticut Mental Health Center, School of Medicine, Yale University. 34 Park Street, New Haven. Connecticut 06519

Sir: Duncan and colleagues have produced an informative review of a complex subject (Psychiatric Bulletin, July 1997, 21, 422-425). The article mentions tardive dystonia only briefly and, understandably, the discussion is weighted towards the management of classic tardive dyskinesia. We wish to comment on the role of botulinum toxin in this area. It is conceded that dystonia occurring as the sole or predominant abnormality of movement among patients with tardive dyskinesia is relatively uncommon. Yassa et al (1992) documented a prevalence ratio for tardive dystonia of $2 \%$ in a prospective study of elderly patients receiving neuroleptic drugs. In comparison orobuccal-lingual stereotypies or stereotypies elsewhere were present in approximately $30 \%$ of the same group. However, in the series of 100 consecutive patients with tardive dyskinesia examined by Stacy et al (1993) stereotypies were observed in $\mathbf{7 8}$ individuals and dystonic movements in 75 . In only 22 of these cases was there dystonia in isolation and clearly in many cases the movements were coexistent. Furthermore both these authors and others have commented that distinction between dystonic movements and stereotypies may at times be very difficult.

Duncan and colleagues state that botulinum toxin is a useful therapy only in cases of tardive dystonia. This statement deserves qualification. First, there may be a dystonic component within a complex dyskinesia amenable to treatment with botulinum toxin. Second, our clinical experience in Middlesbrough and Newcastle would suggest that the stereotypies of classic tardive dyskinesia can also be ameliorated using botulinum toxin (P. D. and M. H.). Tardive dystonia is, however, more frequently a cause of morbidity than stereotypy and our experience of treating dystonia is greater. We would therefore encourage psychiatrists faced with intractable and symptomatic stereotypies, rarer tardive phenomena such as myoclonus and tremor or complex dyskinesias to consider referral to a botulinum toxin clinic even in the absence of a purely dystonic syndrome. Only with such referrals will the true value of botulinum toxin in the treatment of tardive dyskinesias became apparent.

Stacy, M., Cardoso, F. \& Jankovic, J. (1993) Tardive stereotypy and other movement disorders in tardive dyskineslas. Neurology. 43. 937-941.

YASSA. R., NASTASE, C.. DUPONT, D., et al (1992) Tardive dyskinesia in elderly psychiatric patients: a five year study. American Joumal of Psychiatry. 149. 1206-1211.

P. DUFFeY, Lecturer, Department of Clinical Neurosciences, University of Newcastle upon Tyne; J. A. HollaND, Specialist Registrar in Psychiatry, Royal Victoria Infirmary. Newcastle upon Tyne; and M HAWTHORNE, Consultant Otolaryngeal Surgeon, North Riding Infirmary. Newport Road, Middlesborough, Cleveland

\section{Tarasoff and the duty to warn third parties}

Sir: We were interested to read the editorial by Turner \& Kennedy (Psychiatric Bulletin. August 1997, 21, 465-466). They suggest that psychiatric practice in the UK, has altered in recent years towards an increased likelihood of warning third parties, who may be at risk. They relate this to post-Tarasoff discussions and recent UK enquiries (Ritchie et al, 1994).

In 1995 we conducted a postal survey of local Glasgow psychiatrists in which we asked them to indicate their likely response to vignettes which posed issues of confidentiality. We received 53 responses $(59 \%$ of total), 19 respondents were consultants (35.8\%). The first vignette described a 17-year-old out-patient living with her parents and younger sisters who discloses sexual abuse by her father. The patient requests confidentiality. In response 